\title{
Postural Training in Age-Related Macular Degeneration Subjects: Issues and Impact
}

\author{
Hortense Chatard ${ }^{* 1,2}$ and Maria Pia Bucci ${ }^{1,2}$ \\ ${ }^{1}$ UMR 1141, Institut National de la Santé et de la Recherche Médicale - Université Paris 7, France \\ ${ }^{2}$ Vestibular and Oculomotor Evaluation Unit, Robert Debré University Hospital, France
}

Received: 制: September 27, 2018; Published: October 03, 2018

*Corresponding author: Hortense Chatard, UMR 1141, Institut National de la Santé et de la Recherche Médicale - Université Paris 7 , Robert Debré University Hospital, Paris, France

Abbreviations: AMD: Age-Related Macular Degeneration; IVT: Intravitreal Injection; VEGF: Vascular Endothelial Growth Factor; CDP: Center of Pressure

\section{Opinion}

Age-related macular degeneration (AMD) is the leading cause of visual impairment and blindness after fifty years old in developed countries [1,2]. It is estimated AMD will affect 288 million of elderly in 2040 [3]. This pathology is defined by a uni- or bilateral progressive degeneration of photoreceptors in macular area, peripheral vision is conserved. The early level of AMD is characterized by an accumulation of extracellular material ("drusen") underneath the retinal pigment epithelium and/or irregularities of retinal pigment epithelium. At the advanced level of AMD, the disease gets complicated with a geographic atrophy in dry AMD, or a choroidal neovascularization (growth of pathologic blood vessel from the choroide into the subretinal space) in the wet AMD. This one just affects $10-15 \%$ of AMD subjects but emerges and progresses quickly to blindness without intravitreal injection (IVT) of anti-VEGF [4]. Thus, the majority of patients (dry AMD) has no curative treatment, loses visual acuity and his autonomy step by step [5]. AMD gives functional disability (risk of falls, difficulty reading, driving restriction, etc). Some authors evaluated that $33 \%$ of subjects older than 65 years have experienced at least one fall per year $[6,7]$. The loss of autonomy in elderly subjects generates also an augmentation of some pathologies (anxiety and depressive disorders, cardiovascular and metabolic diseases, etc) with a high medical cost [8-10]. One of the solutions to reduce the functional disability and preserve the autonomy of AMD subjects is the development of low-vision rehabilitation. Nowadays, this coverage lacks of evidence and studies while the functional benefit seems admitted by patients.

Postural control is an elaborated process which allows a coordinated relationship of body segments [11,12], and is controlled by vestibular, proprioceptive, and visual information [13-15]. The vestibular system contributes to postural stability with eyes open [16]. Vision and proprioception participate to the detection of slow movements in the visual environment. When the visual or the vestibular system is affected, subjects need to compensate with other sensorial inputs [17]. Some visual factors have a high impact of postural stability and falls: contrast sensitivity and visual field loss [18]. The visual impairment subjects due to increase their somatosensory contribution in order to conserve a good postural stability [19]. However, mechanoreceptors sensibility decreases with aging as well as the capacity of treatment of sensorial information by the central nervous system [20]. Thus, AMD subjects have a deficit of postural control and poor postural adaptive mechanisms [21]. Few studies investigate the impact of AMD on postural control probably because of difficulty of recruitment (age, comorbidities, etc). Most of them use the visual acuity like inclusion criteria. In our past study, we choose to compare the impact of unilateral vs. bilateral AMD on postural sway, and the influence of different visual conditions [21]. Our results showed that postural parameters (surface area and the antero-posterior displacement of the center of pressure, $\mathrm{CdP}$ ) are larger in bilateral AMD subjects than in unilateral AMD subjects; and that in eyes closed condition, AMD subjects are more instable than healthy agematched subjects. We explained this result by the low mobility and degraded physical performances observed in AMD subjects. Such hypothesis is confirmed by previous studies [9,22]. With aging, we note a muscular deterioration. Moreover, the body stability needs interactions between skeletal muscles and sensorial inputs hence a postural instability [23].

There is no age limit to train visual and postural capacities, even if cerebral plasticity decreases. Some studies investigate the impact of visual and/or postural training in AMD subjects [24,25]. Our previous study seemed shown that postural stability was better 
in dominant eye viewing condition than in binocular eye viewing condition in AMD subjects [21]. This result could be explained by a worse binocular visual acuity than dominant eye visual acuity when there is a difference between visual acuity of each eye for instance due to AMD [26]. Park et al. (2011) showed that in elderly subjects there is a statistical difference between postural stability in dominant eye viewing vs non-dominant eye viewing, which is not found in young subjects [27]. These authors suggested that elderly subjects have a high dependency on the dominant eye Moreover, in clinical observation, few AMD patients closed their non-dominant eye for some activities (for instance during reading). This comment is a line of thought of new rehabilitation techniques development. We know also that oculomotor training (for instance, eccentric viewing training, microperimetric feedback) improves reading speed in AMD subjects [28,29]. Based on all these findings, we make the hypothesis that oculomotor training, improving the accuracy of visual input capture, could improve postural stability. Please note that a first step in oculomotor training should be the wearing adapted glasses because of the pathology. Unfortunately, many AMD subjects have multifocal glasses, which increase postural instability and fatigability during a reading task [30]. To conclude, we need evidence of the impact of postural training on AMD subjects in order to decrease the functional disability and to give more autonomy to patients. One of our ongoing study aims to develop efficient postural rehabilitation.

\section{References}

1. Augood CA, Vingerling JR, de Jong PT, Chakravarthy U, Seland J, et al (2006) Prevalence of age-related maculopathy in older Europeans: the European Eye Study (EUREYE). Arch Ophthalmol 124(4): 529-535.

2. Klein R, Chou CF, Klein BE, Zhang X, Meuer SM, et al. (2011) Prevalence of age-related macular degeneration in the US population. Arch Ophthalmol 129(1): 75-80.

3. Wong WL, Su X, Li X, Cheung CMG, Klein R, et al. (2014) Global prevalence of age-related macular degeneration and disease burden projection for 2020 and 2040: a systematic review and meta-analysis. Lancet Glob Health 2(2): e106-e116.

4. Wong T, Chakravarthy U, Klein R, Mitchell P, Zlateva G, et al. (2008) The Natural History and Prognosis of Neovascular Age-Related Macular Degeneration. Ophthalmology 115(1): 116-126.

5. Schmidt Erfurth U, Waldstein SM (2016) A paradigm shift in imaging biomarkers in neovascular age-related macular degeneration. Prog Retin Eye Res 50: 1-24.

6. Campbell AJ, Borrie MJ, Spears GF (1989) Risk factors for falls in a community-based prospective study of people 70 years and older. J Gerontol 44(4): 112-117.

7. Wood JM, Lacherez P, Black AA, Cole MH, Boon MY, et al. (2011) Risk of falls, injurious falls, and other injuries resulting from visual impairment among older adults with age-related macular degeneration. Invest Ophthalmol Vis Sci. 52(8): 5088-5092.

8. McCloud C, Lake S (2015) Understanding the patient's lived experience of neovascular age-related macular degeneration: a qualitative study. Eye 29(12): 1561-1569.

9. Loprinzi PD, Swenor BK, Ramulu PY (2015) Age-Related macular degeneration is associated with less physical activity among US adults: cross-sectional study. PLoS ONE 10: e0125394.

10. Carroll NV, Slattum PW, Cow FM (2005) The cost of falls among the community-dwelling elderly. J Manag Care Pharm. 11(4): 307-316.
11. Paillard J (1971) Les déterminants moteurs de l'organisation de l'espace. Cah Psychol 14: 261-316.

12. Gurfinkel VS, Shik ML (1973) Motor Control Boston, MA: Springer.

13. Nashner LM (1979) Organization and programming of motor activity during posture control. Prog. Brain Res 50: 177-184.

14. Horak FB, Shupert CL (1994) Role of the vestibular system in postural control. Vestib Rehabil 13: 69-81.

15. Fetter M, Dichgans J (1996) Vestibular neuritis spares the inferior division of the vestibular nerve. Brain J Neurol 119: 755-763.

16. Fitzpatrick R, McCloskey DI (1994) Proprioceptive, visual and vestibular thresholds for the perception of sway during standing in humans. J Physiol 478 (Pt1): 173-186.

17. Brandt T (2003) Vertigo: Its Multisensory Syndromes. London; New York, NY: Springer.

18. Wood JM, Lacherez PF, Black AA, Cole MH, Boon MY, et al. (2009) Postural stability and gait among older adults with age-related maculopathy. Invest Ophthalmol Vis Sci 50(1): 482-487.

19. Kotecha A, Chopra R, Fahy RT, Rubin GS (2013) Dual tasking and balance in those with central and peripheral vision loss. Invest Ophthalmol VisSci.54(8): 5408-5415.

20. Qiu F, Cole MH, Davids KW, Hennig EM, Silburn PA, et al. (2012) Enhanced somatosensory information decreases postural sway in older people. Gait Posture 35(4): 630-635.

21. Chatard H, Tepenier L, Jankowski O, Aussems A, Allieta A, et al. (2017) Effects of Age-Related Macular Degeneration on Postural Sway. Front Hum Neurosci 11:158.

22. Chomistek AK, Manson JE, Stefanick ML, Lu B, Sands Lincoln M, et al. (2013) Relationship of sedentary behavior and physical activity to incident cardiovascular disease: results from the Women's Health Initiative. JAm Coll Cardiol 61(23): 2346-2354.

23. Shumway Cook A, Taylor CS, Matsuda PN, Studer MT, Whetten BK, et al. (2013) Expanding the scoring system for the Dynamic Gait Index. Phys Ther 93(11): 1493-1506.

24. Radvay X, Duhoux S, Koenig Supiot F, Vital Durand F (2007) Balance training and visual rehabilitation of age-related macular degeneration patients. J Vestib Res 17(4): 183-193.

25. De Vries A, Faber G, Jonkers I, Van Dieen JH, Verschueren SMP (2017) Virtual reality balance training for elderly: Similar skiing games elicit different challenges in balance training. Gait Posture 59: 111-116.

26. Azen SP, Varma R, Preston Martin S, Ying Lai M, Globe D, et al. (2002) Binocular visual acuity summation and inhibition in an ocular epidemiological study: the Los Angeles Latino Eye Study. Invest Ophthalmol Vis Sci 43(6):1742-1748.

27. Park RY, Kee HS, Kang JH, Lee SJ, Yoon SR, et al. (2011) Effect of Dominant Versus Non-dominant Vision in Postural Control. Ann Rehabil Med 35(3): 427-431.

28. Hamade N, Hodge WG, Rakibuz Zaman M, Malvankar Mehta MS (2016) The effects of low-vision rehabilitation on reading speed and depression in age-related macular degeneration: a meta-analysis. PlosOne 11(7): e0159254.

29. Ramírez Estudillo JA, León Higuera MI, Rojas Juárez S, Ordaz Vera ML, Pablo Santana Y, et al. (2017) Visual rehabilitation via microperimetry in patients with geographic atrophy: a pilot study. Int J Retina Vitreous 3: 21.

30. Lord SR (2006) Visual risk factors for falls in older people. Age Ageing 35-52: ii42-ii45. 
ISSN: 2574-1241

DOI: $10.26717 / B J S T R .2018 .09 .001816$

Hortense Chatard. Biomed J Sci \& Tech Res

(c) (P) This work is licensed under Creative

Submission Link: https://biomedres.us/submit-manuscript.php

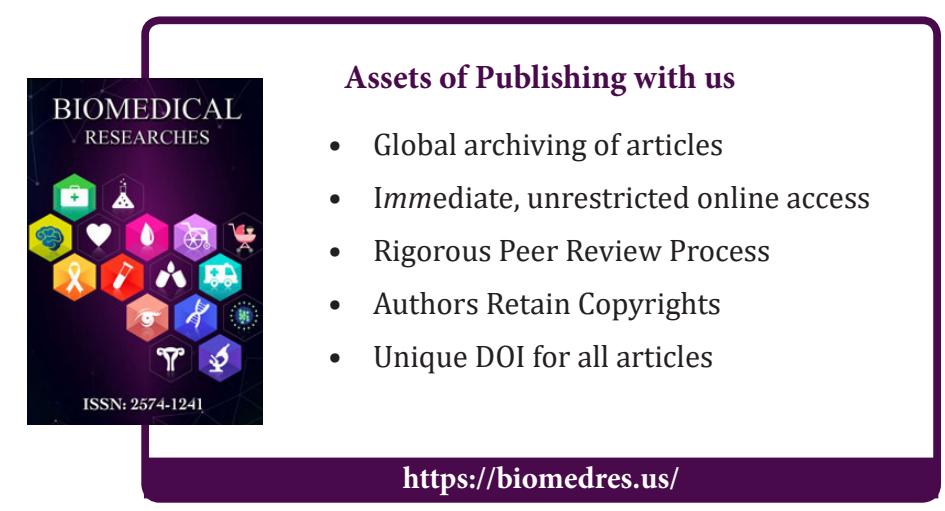

